\title{
COMITÊS DE TERRA URBANA: LOGRANDO A CONCRETIZAÇÃO DA REGULARIZAÇÃO FUNDIÁRIA EM PROL DA MORADIA DIGNA
}

\author{
URBAN LAND COMITTEES: ACHIEVING THE CONCRETION OF THE \\ GROUND ADJUSTMENT IN SUPPORT OF DECENT HOUSING
}

\author{
AleXANDRe RiginiK ${ }^{1}$
}

Recebido em: 08/06/2014

Aprovado em: 13/04/2015

\section{RESUMO}

O presente trabalho teve por finalidade analisar a experiência dos Comitês de Terra Urbana na Venezuela. Trata-se de uma iniciativa legislativa que visa à consecução dos mandamentos da Constituição da República daquele país, de 1999, no sentido de garantir o direito à moradia digna e à participação popular como protagonistas das tomadas de decisão. Destarte, buscou-se analisar a dinâmica dos Comitês de Terra urbana nesse contexto em que se busca aprimorar a gestão democrática, com a finalidade de concretizar o direito à cidade. Para isso, procedeu-se ao diagnóstico da evolução das políticas públicas relacionadas à habitação na Venezuela até os dias atuais, bem como à análise da legislação pátria, realizando um cotejo entre o marco legal e a prática da atuação dos comitês. Por fim, discorreu-se a respeito do contexto paradoxal da república Bolivariana, situando a autonomia e eficiência dos Comitês nessas relações dialéticas.

Palavras-chave: Comitês de Terra Urbana; Venezuela; Moradia digna; Participação popular.

\begin{abstract}
This work aimed at analyze the experience of the Urban Land Committees in Venezuela. This is a legislative initiative that aims the achievement of the Constitution's commandments of that country, dated in 1999 to ensure the right to adequate housing and the right to popular participation as actors in decision-making. Thus, we sought to analyze the dynamics of the Urban Land Committees within this context that seeks to improve the democratic administration, in order to realize the right to the city. For this, we made the diagnosis of the evolution of public policies related to housing in Venezuela to the present day, and proceeded to the analysis of country legislation, making a comparison between the legal framework and the practice of the committees action. Finally, a conclusion was reached regarding the paradoxical context of the Bolivarian Republic, placing the autonomy and efficiency of these Committees within those dialectical relations.

Keywords: Urban land committees; Venezuela, Decent housing; popular participation.
\end{abstract}




\section{Introdução}

Hoje se encontra na pauta internacional de redes e organizações ligadas à questão da moradia, especificamente, ou do desenvolvimento e planejamento urbano, em geral, o debate em torno da consolidação do direito à cidade como direito humano coletivo. Isso se deve ao fato de as cidades atuais, principalmente localizadas nos países subdesenvolvidos, não corresponderem ao ideal de cidade desejado, em que se preza pela inclusão social e pela justa distribuição dos ônus e benefícios do processo de urbanização, de modo que a população consiga usufruir, de maneira equânime, as riquezas, as culturas, os bens e os conhecimentos que a cidade oferece e que, acima de tudo, todos os cidadãos tenham acesso a uma moradia digna, munida dos componentes mínimos preconizados pelo comentário geral $n^{0} 4$ do Comitê sobre Direitos Econômicos, Sociais e Culturais da Organização das Nações Unidas (ONU) ${ }^{2}$.

Pelo contrário, os modelos de desenvolvimento experimentados pela maioria das cidades do mundo se caracterizam por estabelecer níveis de concentração de renda e poder, gerando pobreza e exclusão/segregação social, o que contribui para a depredação do meio ambiente. Esses processos favorecem a proliferação de grandes áreas urbanas em condições de pobreza, precariedade e vulnerabilidade diante dos riscos naturais.

Contribuem para isso as políticas públicas que, ao desconhecer os aportes dos processos de produção popular para a construção das cidades e da cidadania, violentam a cidade urbana. Graves consequências resultam desse processo, como os despejos massivos, a segregação e a consequente deterioração da convivência social. Esse contexto favorece o surgimento de lutas urbanas que, devido ao seu significado social e políti-

${ }^{2}$ Os elementos mínimos para uma moradia adequada, previstos pelo comentário $\mathrm{n}^{\circ} 4$ do Comitê sobre Direitos Econômicos, Sociais e Culturais da ONU, são: segurança legal da posse, disponibilidade de serviços, materiais, facilidades e infraestrutura, custo acessível, habitabilidade, acessibilidade, localização e adequação cultural. co, ainda são fragmentadas e incapazes de produzir mudanças significativas no modelo de desenvolvimento vigente.

Dentro desse contexto de busca pela efetivação do direito à cidade, em que a população pobre seja notada e em que, por conseguinte, as demandas populares sejam atendidas, o presente trabalho irá proceder ao estudo e à análise de uma experiência ocorrida na Venezuela, em que se busca exatamente efetivar o direito à cidade, visando garantir o acesso à terra urbanizada à população de baixa de renda, mediante uma cogestão entre a comunidade e o Poder Público.

Conforme é cediço, a exegese que envolve a compreensão do direito à cidade concebe o direito à moradia adequada e a gestão democrática das cidades como componentes desse novel direito humano. Nessa seara, os Comitês de Terra Urbana (CTU) surgem como uma política pública tendente a concretizar esses dois elementos caracterizadores do direito à cidade, uma vez que visam essencialmente garantir a regularização fundiária, bem como a regularização integral dos bairros pobres, em seu aspecto jurídico e físico, mediante uma participação popular ativa, em uma verdadeira cogestão com o Poder Público.

Trata-se dos CTU de uma das organizações sociais de base popular com maior número de membros e com mais ampla trajetória enquadrada na proposta de democracia participativa, sancionada na Constituição da República bolivariana da Venezuela de 1999 por meio da proteção do direito à cidade e a uma moradia digna.

Segundo informação da Oficina Técnica Nacional para a Regularização da Terra, no ano de 2006, existiam aproximadamente seis mil CTU, com presença na maior parte dos bairros pobres do país e com uma cobertura de cerca de um milhão de famílias ${ }^{3}$.

Sendo assim, o presente trabalho possui a finalidade de analisar o contexto em que foi estabelecida a política públi${ }^{3}$ Programa Nacional de Regularización de la Tierra Urbana. Oficina Técnica Nacional de Regularización de la Tenencia de la Tierra Urbana (2006). 
ca em questão, bem como o marco legal que acompanhou sua institucionalização.

No mais, discorrer-se-á acerca do funcionamento prático dos Comitês, explicando a dinâmica de sua atuação frente ao Poder Público. Também serão indicados outros atores sociais, a fim de garantir uma correta visualização a respeito do cenário político da Venezuela. Por fim, verificar-se-á se os CTU são uma medida eficaz em relação aos objetivos para os quais foram criados - garantir uma moradia adequada à população de baixa renda, mediante o incremento da participação popular como efetivos gestores da política pública, e não apenas como beneficiários.

2 Cenário das cidades antes da Constituição de 1999: cidades excludentes e segregadoras - ineficiência de gestão e das políticas públicas

Uma das características do padrão de urbanização na Venezuela tem sido a configuração de um espaço altamente segregado socialmente como consequência do modelo petroleiro, que gerou fortes desequilíbrios sociais, econômicos e territoriais. Mais de $50 \%$ da população vive nos denominados assentamentos informais ou bairros pobres, sem acesso à propriedade legal do solo que ocupam e sem redes de articulação com a cidade formal. Em 1990, segundo M. Negrón, a população venezuelana dos setores populares havia construído, com seu esforço, entre um terço e metade das cidades na Venezuela ${ }^{4}$.

Além dos espaços segregados, os bairros pobres são espaços de exclusão, já que têm as maiores deficiências quanto a moradias dignas, serviços básicos como água e equipamentos públicos como escolas e centros de saúde. Seus habitantes têm as taxas mais baixas de escolaridade e as mais altas de desemprego, de morbidade e mortalidade infantil e de homicídios. Enfim, são es-

${ }^{4}$ Negrón, M. (1990). Ciudad formal y ciudad informal: una sola ciudad, Revista Investigación y Gerencia, vol. 7, no 33, Caracas. paços de negação dos direitos humanos fundamentais inscritos na Constituição bolivariana de 1999.

No geral, as políticas de moradia do Estado têm se caracterizado por uma grande desarticulação, fato que propiciou altas demandas não satisfeitas de moradia e formas de organização social que se traduziram em um mercado informal de construção e comercialização da cidade. Desde o início da democracia em 1958, e inclusive durante a ditadura de Marcos Perez Jimenez, o Estado Venezuelano adjudicou-se à responsabilidade pela resolução ou melhoria dos bairros pobres e de moradia ${ }^{5}$.

De fato, muitas das políticas de melhoria de bairros se centravam na produção maciça de moradias ou no financiamento de empreendimentos habitacionais isolados, o que obedece aos benefícios de uma economia petroleira em ascensão que permitia ao Estado centralizar o tema da construção imobiliária. É assim que o Estado venezuelano adotou um papel paternalista e atuou como produtor, gestor e financiador não apenas dos planos e projetos urbanos, mas também das moradias de interesse social ${ }^{6}$.

No entanto, a carência ou as deficiências de um marco jurídico sobre a participação cidadã que sustentasse os programas de melhoria de bairros contribuiu ao vazio da participação comunitária em tais programas. De 1958 a fins dos anos 70, criaram-se instituições dirigidas a resolver a problemática dos bairros pobres, como a Fundación para El Desarrollo de La Comunidad e Fomento Municpal (Fundacomun) ${ }^{7}$ (1962) e o Fondo Nacional de Desarrollo Urbano (Fondur) $^{8}$ (1975); criaram-se cooperativas de habitação (1959-1976); realizaram-se produções maciças de

${ }^{5}$ García-Guadilla, María-Pilar (2007). "Ciudadanía y autonomía en las organizaciones sociales bolivarianas: los Comités de Tierra Urbana como movimientos sociales". Cuadernos del cendes año 24. n 66, Tercera Época, septiembre-diciembre, 2007. P. 50.

${ }^{6}$ Baldó, J. (2004). «La política de vivienda para Venezuela», en C. Genatios, comp., Venezuela en perspectiva, Caracas, Fondo Editorial Cuestión. Pg. 349

${ }^{7} \mathrm{El}$ objetivo fundamental de esta institución es el financiamiento de los desarrollos habitacionales y de la infraestructura de servicios, así como también la asistencia técnica a los Concejos Municipales.

también la asistencia técnica a los Concejos Municipales.
${ }_{8}^{8}$ Fondur se centró en un programa de adquisición de tierras. 
moradias, urbanizações populares e equipamentos de bairros (1969-1974); e desenvolveu-se o subsídio habitacional.

Apesar dessas iniciativas, a falta de continuidade e seu caráter isolado levaram ao aumento do déficit de moradias e à deterioração progressiva da qualidade de vida dos moradores dos bairros pobres. Aliado a isso, a década de 90 estava marcada por uma profunda crise econômica, política e social devido à incapacidade do Estado centralista de oferecer soluções à problemática dos bairros pobres, que, na época, afetava mais de 50\% da população que residia nas cidades ${ }^{9}$.

Durante esse período, consolidou-se a descentralização política, a qual se apoiou no marco jurídico aprovado em 1989 e 1990. Como parte do processo de descentralização, transferiram-se competências e poder do nível central aos governos regionais e regulamentou-se a organização e participação comunitária em nível local.

Entretanto, essa transferência de poder assumiu mais um papel de delegação de funções e competências do que de recursos econômicos correspondentes. Ademais, a participação comunitária limitou-se ao âmbito informativo e consultivo.

Desse modo, é possível afirmar que o processo descentralizador estava mais dirigido a aperfeiçoar o modelo de democracia representativa e a fazer trocas - para que tudo permanecesse igual - do que a incorporar instrumentos legais que dessem base ao aprofundamento da democracia ${ }^{10}$.

Apesar do já exposto, houve alguns avanços em matéria de melhorias dos bairros pobres, já que em 1990 se criou o Conselho Nacional da Habitação e aprovou-se a Lei de Política Habitacional, a qual foi modificada em 1993. Essa Lei institucionalizou o Sistema Nacional de Assistência Técnica, que se converteu em um intermediário entre o Estado e o setor comunitário, propiciando a criação das Organizações Comunitárias de Habitação ${ }^{11}$.

Alguns dos aportes mais significativos desse período foram o Programa Nacional de Equipamentos de Bair- $\operatorname{ros}^{12}$ e o Projeto Cameba ${ }^{13}$, os quais se centraram na melhoria da qualidade de vida dos habitantes dos bairros pobres, estabelecendo como prioridade a incorporação das comunidades no processo de habilitação dos bairros.

\section{Constituição de 1999: incorporação do direito à cidade e do direito à par- ticipação - chamamento à democra- cia participativa}

A cidadania é o estatuto da pessoa que habita a cidade, em que se reconhecem os "direitos individuais e de expressão e construção de identidades coletivas de democracia participativa e de igualdade básica entre os habitantes"14.

Devido à relação dialética que existe entre a cidadania e a cidade, os valores vinculados a esta só emergem quando o estatuto da cidadania é "uma realidade material e não só um reconhecimento formal"15. Portanto, a construção de cidadania deve ser entendida como um processo ou uma dinâmica transformadora que permite converter o cidadão em um sujeito de direitos e deveres que pode ter efeito sobre o governo da cidade.

O reconhecimento do estatuto da cidadania, corolário do direito à cidade, do qual se extrai o reconhecimento dos direitos individuais, dentre os quais se encontram a moradia e o direito de participação, foram sancionados na Constituição da República Bolivariana da Venezuela, de 1999; sua concretização nas políticas do governo tem tido distintas fases.

Com a chegada de Hugo Chávez Frías à Presidência da Venezuela em 1999, as políticas públicas reorienta-

\footnotetext{
${ }^{9}$ Rivas, M. (2004). «El problema de los barrios», Revista SIC, Dossier, $\mathrm{n}^{\mathrm{o}} 665$, Caracas. Pg. 219.

${ }^{10}$ García-Guadilla, M.P. (2002). «Democracy, Decentralization, and Clientelism: New Relationships and Old Practices», Latin American Perspectives, Issue 126, vol. 29, no 5, pp. 90-109.

${ }^{11}$ Rivas, M. (2004). «El problema de los barrios», Revista SIC, Dossier, $\mathrm{n}^{\mathrm{o}} 665$, pg. 221 , Caracas.

${ }^{12}$ Decreto 140 (20/04/1994) de iniciativa do Fundacomun.

${ }^{3}$ Regulado pela Lei del Subsistema de Política Habitacional (10/98) com atuação em dois bairros: La Vega (UPF-10) y Petare Norte (UPF- 04). As siglas UPF correspondem à Unidad de Planificación Física. ${ }^{14}$ Borja, J. (2003). La ciudad conquistada, Madrid, Alianza Editorial. Pg. 22.

${ }^{15}$ Op. Cit. P. 22
} 
ram-se para os setores mais pobres, e, sob o lema da inclusão dos excluídos, propuseram-se trocas estruturais na concepção dos bairros e na forma de resolver os problemas que afetavam a população pobre, incluindo a moradia.

Para lograr esse objetivo, o presidente Chávez ${ }^{16}$ propôs o aprofundamento do modelo da democracia participativa e a atenção para os venezuelanos excluídos econômica, social e espacialmente. Tendo em vista que os habitantes dos bairros pobres estão duplamente excluídos (de forma material e simbólica $)^{17}$ do direito à cidade e à cidadania, ou de direitos que deve oferecer a cidade, uma das primeiras propostas do presidente Chávez para a nova Constituição foi a criação de novas figuras participativas e a ampliação dos mecanismos de participação para incorporar a população na solução dos problemas existentes ${ }^{18}$.

Ademais, devido aos altos déficits acumulados de moradias, a Comissão Nacional de Habitação ${ }^{19}$, com base no direito à moradia sancionado no artigo 82 da Constituição Bolivariana da República da Venezuela ${ }^{20}$, propôs uma nova política nacional de habitação, orientada a saldar a dívida social adquirida com a população de baixa renda, que, apesar de ter autoconstruído grande parte das cidades venezuelanas por falta de ajuda do governo, habita espaços que carecem dos serviços básicos e de infraestrutura mais elementares de-

${ }^{16}$ Menciona-se Chávez ao invés de Governo porque a maior parte dessas decisões é de sua única responsabilidade, já que em muitos casos se estabeleceram mediante decretos presidenciais.

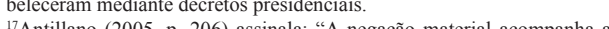
"Antillano (2005, p. 206) assinala. "A negação material acompanha a negação sim (2005, p. nas, são a cidade fora da cartografla. Não apas, não são registrados nos cadastros e censos, não se contam em suas crônicas, não são considerados na hora de inventariar seu patrimônio. Os bairros não existem na retórica da cidade salvo como perigo ou anomalia... O bairro se define mais pelo que carece do que pelo que é, por sua negação mais do que por sua afirmação".

${ }^{18} \mathrm{CBRV}$, art. 70: "Son medios de participación y protagonismo del pueblo en ejercicio de su soberanía [...] en lo social y económico: las instancias de atención ciudadana, la autogestión, la cogestión, las cooperativas en todas sus formas incluyendo las de carácter financiero, las cajas de ahorro, la empresa comunitaria y demás formas asociativas guiadas por los valores de la mutua cooperación y la solidaridad. La ley establecerá las condiciones para el efortiono funcionamiento de los medios de participación previstos en este artículo".

"Estudios de Conavi estiman que existe un déficit acumulado de 620.000 unidades habitacionales, en donde 1 millón ya existe y requiere mejoras o remodelaciones, generando una necesidad neta de 620.000 unidades nuevas" (BALDÓ, 2004, p. 350). vido ao padrão de espontaneidade com que foram construídos.

O eixo de ação dessa política se baseia em um componente urbano e em outro social. O componente urbano está dirigido à atenção habitacional às famílias por meio da doação de obras que contribuam à transformação do hábitat e à melhoria de seus padrões de vida; ao passo que o componente social tem como objetivo promover novos canais de participação comunitária ativa para a gestão coletiva da cidade, o que significa que as comunidades organizadas têm um papel importante no planejamento e na gestão urbana de áreas de bairros, tal como prescreve a Constituição de 1999. Por outro lado, a reivindicação do direito constitucional à moradia e à propriedade da terra na qual se localiza não é novidade nem se inseriu em um vazio organizacional, já que os Governos anteriores haviam levantando a questão a partir de diferentes enfoques. Além disso, ademais, uma elevada porcentagem da população afetada por problemas de moradia se mobilizou no passado sob diferentes formas organizacionais para fazer com que suas demandas fossem ouvidas, incluindo aquela de regularização da posse da terra.

Do ponto de vista organizacional, um dos antecedentes mais importantes foi a Assembleia de Bairros de Caracas, fundada em 1991, em resposta à proposta da mesa do povo do primeiro Encontro Internacional de Reabilitação de Bairros, e que durou até 1993 (ANTILLANO, 2005, p. 207) ${ }^{21}$.

A dinâmica participativa e o enfoque de direitos inseridos na Constituição de 1999 propiciaram novos modelos de organização comunitária para reclamar os mencionados direitos. Na atualidade, a organização social popular está sendo

\footnotetext{
${ }^{20} \mathrm{CBRV}$, art. 82: «Toda persona tiene derecho a una vivienda adecuada, segura, cómoda, higiénica, con servicios básicos esenciales que incluyan un hábitat que humanice las relaciones familiares, vecinales y comunitarias. La satisfacción progresiva de este derecho es obligación compartida entre los ciudadanos y ciudadanas y el Estado en todos sus ámbitos. El Estado dará prioridad a las familias y garantizará los medios para que éstas, y especialmente las de escasos recursos, puedan acceder a las políticas sociales y al crédito para la construcción, adquisición o ampliación de viviendasy.
} 
patrocinada pelo Governo e está sob o amparo da Constituição e do modelo político que incentiva a participação na solução das demandas dos setores pobres, motivo pelo qual o Governo tem direcionado recursos financeiros consideráveis e recursos técnicos provenientes do boom do petróleo às Organizações Populares, que constituem, supostamente, sua base de apoio político.

Esses fatores explicam a explosão de formas organizacionais promovidas pelo Governo, dentre as quais se encontram os Círculos Bolivarianos, os Comitês de Terra Urbana (CTU), dentre muitas outras.

Apesar disso, diferentemente dos processos de organização que representaram as Assembleias de Bairros e que permitiram manter a autonomia do povo frente ao Estado e aos partidos políticos, as novas formas organizacionais propostas, derivadas da concepção da democracia participativa e protagonistas da Constituição de 1999, estão sendo promovidas a partir de cima, isto é, da Presidência da República $^{22}$, como é o caso dos CTU, que surgiram por Decreto presidencial.

\section{Os comitês de terra urbana: marco legal e funcionamento}

Apesar dos elementos comuns que compartilham os Comitês de Terra Urbana (CTU), tais como sua identificação com a comunidade organizacional e a demanda de regularização da posse da terra onde se encontram as moradias,

\footnotetext{
${ }^{21}$ Antillano, A. (2005). «La lucha por el reconocimiento y la inclusión en los barrios populares: la experiencia de los Comités de Tierras Urbanas», Revista Venezolana de Economía y Ciencias Sociales, vol. 11, no 3 , pp. 207.

${ }_{22}$ Uma das primeiras figuras a promover a participação comunitária surgidas dentro do governo do presidente Chávez, que desde sua campanha eleitoral se declarou a favor da organização popular, foram os Círculos Bolivarianos (CB), os quais se criaram mediante decreto presidencial e fundamentavam-se, segundo o presidente, no artigo 52 da CBRV. Os mesmos foram atribuídos ao Ministério da Secretaria da República, tendo como um de seus objetivos: organização popular para lograr o bem-estar da comunidade: [...] saúde e moradia (http://derechos.org.ve/publicaciones). Apesar disso, os $\mathrm{CB}$ nasceram estritamente vinculados com a ideologia bolivariana e com o partido do presidente, o Movimento V República (MVR). Essa associação política, assim como o perfil político de seus integrantes, reduziu consideravelmente a diversidade de setores de seus intes desvirundo-os dos objetivos originais e facilos participantes, desvirtuando-os dos objetivos originais e facilitando sua CÍA-GUADILLA, 2003).
}

existe grande heterogeneidade nas práticas que desenvolvem esses atores. De fato, os CTU são altamente heterogêneos em termos da tradição jurídica da terra ${ }^{23}$; dos atores econômicos, sociais e políticos com os quais interatuam e estabelecem alianças e articulações; da tradição de luta de seus membros; da etapa no processo de regularização na qual se encontram; e inclusive das estratégias que utilizam para lograr seus objetivos ${ }^{24}$.

Em função dessas diferenças, a avaliação sobre se os CTU têm um potencial transformador do CTU como movimento social e, por isso, a capacidade de construir novas subjetividades e projetos de sociedade autônomos ou se, pelo contrário, podem ser cooptados e reorientados para objetivos políticos eleitorais ou para práticas neoclientelistas passa pela compreensão e comparação de suas duas faces ou dimensões: a legal-institucional e a da práxis.

4.1 Bases legais e institucionais dos CTU: o Decreto n. ${ }^{\circ} 1666$

O texto constitucional e o ordenamento jurídico vigente desde 1999 pretenderam canalizar as demandas de maior participação cidadã que surgiram a partir das críticas à democracia representativa ${ }^{25}$.

A Constituição da República Bolivariana da Venezuela reconhece a obrigação do Estado venezuelano de garantir não só o direito de toda pessoa a uma moradia adequada, como também o direito de todos os cidadãos a participar através de distintos meios nos assuntos públicos e na formação, na execução e no controle da gestão pública (CRBV, arts. 6, 62 e 70). Sob os aludidos pilares constitucionais, sobreveio a promulgação do Decreto Presidencial n. ${ }^{\text {o } 1666 / 02, ~}$ mediante o qual se iniciou o processo de

\footnotetext{
${ }^{23}$ A terra que ocupam pode pertencer ao Estado ou a um particular. No caso da propriedade pública da terra, esta pode pertencer à prefeitura ou ao governo central. Por outro lado, as prefeituras podem facilitar ou dificultar o processo de regularização da posse da terra segundo conforme forem a favor ou contra ele.

${ }^{24} \mathrm{O}$ processo de regularização da posse da terra inicia com a criação do CTU, o levantamento cadastral e a Carta de Bairro, dentre outros, e
} culmina com a adjudicação da titularidade da terra. 
regularização da posse da terra nos assentamentos urbanos populares.

É importante destacar que o artigo 82 do texto constitucional reconhece o direito a uma moradia adequada, no Capítulo "Dos Direitos Sociais e das Famílias", e reconhece os elementos desse direito definidos pelo Comitê de Direitos Econômicos, Sociais e Culturais, em seu comentário geral n. ${ }^{\circ} 4$, datado de 1991. Ao todo, são sete elementos considerados: segurança jurídica da posse; disponibilidade de serviços, materiais, facilidades e infraestrutura; gastos suportáveis; habitabilidade; acessibilidade; lugar; e adequação cultural.

O objetivo do Decreto n. ${ }^{\circ} 1666$ foi iniciar o processo de regularização da posse da terra em bairros e urbanizações populares urbanas do país e submeter à consulta pública o anteprojeto de lei que regeria a matéria ${ }^{26}$, sendo os CTU a forma de organização adotada para este fim. Segundo seu artigo $1^{\circ}$, o aludido Decreto objetiva dar início à participação protagonista das comunidades organizadas, com o fim de regularizar a posse das terras urbanas em urbanizações populares, por meio da devida coordenação interinstitucional.

Nesse sentido, o artigo $3^{\circ}$, inciso I, contempla a criação dos CTU para iniciar o processo de regularização da posse da terra.

Conforme estabelecido pelo próprio Decreto, a Oficina Técnica Nacional $(\mathrm{OTN})$, instância vinculada à Vice -Presidência da República, tem dentre suas funções estimular a participação cidadã mediante a criação dos indigitados Comitês, realizar a inscrição e o registro das informações necessárias

\footnotetext{
${ }^{25}$ Algumas das críticas à democracia representativa têm advindo do questionamento acerca da capacidade dos partidos políticos para mediar os Estados e o cidadão (GACÍA-GUADILLA, 2003; 2005; ELLNER; HELLINGER, 2003; LÓPEZ MAYA, 2005) e a desconfiança diante da própria ideia de delegação do poder, que tem conduzido à delegação de vontade e a abusos de poder (RESTREPO, 2000).

${ }^{26}$ Foram elaborados três projetos de lei: o primeiro, do Partido Primero Justicia, intitulado "Lei de Regularização da propriedade da terra urbana e urbanização dos bairros populares"; o segundo, proposto pelos deputados da bancada do governo da Assembleia Nacional Nicolás Maduro (atual presidente), Carlos Khan, Angel Rodriguez e Luis Francescho, intitulado "Lei de regularização da posse da terra nos assentamentos populares"; e o terceiro, introduzido pelos próprios CTU.
}

sobre os CTU, adiantar procedimentos de coordenação interinstitucional e social necessários para a regularização da posse da terra, reunir e estudar a informação sobre a situação da propriedade e posse da terra em bairros e urbanizações populares e levar a cabo o processo de consulta pública do anteprojeto de Lei de Regularização da posse da terra nos assentamentos populares, que estava para ser votada pelo congresso ${ }^{27}$.

Esse processo de regularização da posse da terra urbana está associado à legislação que regula a posse tanto dos terrenos públicos quanto das terras de propriedade privada. Desse modo, ainda que o Decreto n. ${ }^{\circ} 1666$ abrisse a possibilidade de iniciar o processo de regularização da terra dos assentamentos populares localizados em terrenos de propriedade do Estado, as negociações realizadas sobre as terras privadas eram regidas pelo Código Civil, de modo que, para proceder ao processo de regularização dessas propriedades, exigia-se a promulgação de uma lei especial.

Contudo, no ano de 2006, sobreveio a lei especial, à qual inclusive o Decreto n. ${ }^{\circ} 1666$ fazia menção - Lei Especial de Regularização Integral da Posse da Terra dos Assentamentos Urbanos Populares de 17 de julho de 2006 - que possibilitou a regularização fundiária tanto de propriedade privada como de propriedade pública.

Por outro lado, é importante mencionar que, além de a situação jurídica da terra poder variar de um município a outro, as opções para superar as dificuldades jurídicas também variam entre eles de acordo com as normas que tenham aprovado para regular os processos.

Em agosto de 2004, o Presidente da República anunciou a criação da Missão Moradia, e, em novembro do mesmo ano, os CTU apresentaram sua proposta a essa nova Missão social do governo. A aludida proposta foi produto de um debate nacional que também serviu para fortalecer os espaços de articulação dos

${ }^{27}$ Artigo $3^{\circ}$ do Decreto n. ${ }^{\circ} 1666 / 02$. 
CTU com as "paróquias"28, os municípios e as regiões do país em geral. O elemento fundamental dessa proposta foi a compreensão do processo de regularização da posse da terra como um processo integral que implica a regularização jurídica, urbanística e física.

A regularização jurídica implica a propriedade da terra. A regularização urbanística refere-se ao estabelecimento, por consenso, das normas de convivência que respeitam as particularidades e a idiossincrasia de cada comunidade e cada bairro, sem que isso signifique deixar de levar em consideração o resto da cidade, apontando para um processo constituinte e para um autogoverno comunitário. Por sua vez, a regularização física corresponde ao processo de regularização da infraestrutura do local, com o competente arruamento, a divisão dos lotes e a instalação dos equipamentos públicos essenciais. O instrumento fundamental desse processo é a Carta de Bairro.

Em síntese, o marco legal existente está orientado a desmontar as dinâmicas de segregação espacial que afetam mais da metade da população urbana venezuelana, ampliar as demandas de uma sociedade mais democrática e equitativa e satisfazer as demandas de inclusão, de democratização e de equidade.

\subsection{A estrutura e o funcionamento dos CTU}

A leitura legal institucional dos CTU leva à conclusão de que formalmente devem ser democráticos em sua estrutura e seu funcionamento. De acordo com os estatutos, os CTU são espaços privilegiados da democracia participativa, já que as decisões importantes, incluindo sua própria constituição, devem ser tomadas em Assembleias de Cidadãos ${ }^{29}$

A Oficina Técnica do Município define-os como "modelos de organização

\footnotetext{
${ }^{28} \mathrm{As}$ parroquias são uma unidade político-territorial de menor grau, localizadas dentro dos Municípios. As parroquias urbanas devem possuir, no lizadas dentro dos Municípios. As parroquias urbanas devem possuir, no
mínimo 50.000 habitantes, contando com um órgão de direção e gestão, denominada Junta Parroquial, eleito pela população e composto por cinco membros
}

horizontais e autônomos que têm como objetivo realizar todas as atividades para lograr a aquisição do título da terra de um setor ou comunidade e buscar soluções de problemas de tipo urbano" 30 .

Cada CTU trabalha com o propósito de conquistar a regularização da posse da terra, atuando também nos processos de tomada de decisões sobre a melhoria integral do bairro ou urbanização popular. Segundo as diretrizes da Oficina Técnica dos CTU, o âmbito de ação espacial não deve ser maior de 200 famílias, sua estrutura deve ser democrática e seus integrantes devem ser eleitos através de eleições em Assembleias de Cidadãos levadas a cabo nos setores populares.

Os CTU podem definir a estrutura de comissões, tais como de censo, cadastro, Carta de Bairro, propaganda, recursos, ações comunitárias, relações institucionais ou outras que considerem convenientes para formar seu efetivo funcionamento alinhado a seus objetivos. Essa estrutura deve funcionar de forma horizontal e flexível, prestando contas de suas atividades à respectiva OTN. Por outro lado, o processo de tomada de decisões e o cronograma de atividades devem ser discutidos e aprovados nas Assembleias de Cidadãos, as quais devem ser realizadas periodicamente, tendo sua convocação deve ser divulgada com cinco de dias de antecedência através dos meios de comunicação de que dispor a comunidade ${ }^{31}$.

Para cumprir com as funções estabelecidas no Decreto n. ${ }^{\circ} 1666$, os CTU organizam-se nas comissões que consideram necessárias. Segundo esse Decreto, suas funções são fomentar a discussão e formulação de observações e propostas ao anteprojeto de lei; coletar informações ou inventariar as moradias nos bairros; levantar planos provisionais que permitam identificar os limites

${ }^{29}$ Garcia-Guadilla, María-Pilar (2007). "Ciudadanía y autonomía en las organizaciones sociales bolivarianas: los Comités de Tierra Urbana como movimientos sociales". Cuadernos del cendes año 24. n 66, Tercera Época, septiembre-diciembre, 2007. Pag. 58

poca, septiembre-diciembre, 2007. Pag. 58 "García-Guadilla, María-Pilar (2007). "Ciudadanía y autonomía en la organizaciones sociales bolivarianas: los Comites de Tierra Urbana como movimientos sociales". Cuadernos del cendes año 24. n 66, Tercera Época, septiembre-diciembre, 2007. Pg. 58 
geográficos da comunidade e identificar o ordenamento urbanístico espontâneo e histórico dos bairros, o parcelamento e seus usos; fazer uma lista dos membros da comunidade a fim de elaborar coletivamente um documento de reconhecimento do bairro (Carta do Bairro); e participar no projeto, na execução e na fiscalização das políticas públicas para a reabilitação integral dos bairros.

Para construir os CTU, delimitase, em primeiro lugar, o território de sua abrangência, conhecido como "poligonal", o qual é definido a partir dos usos, dos costumes, da história e da tradição dessa comunidade e não a partir de critérios técnicos. Considerando que os CTU são um grupo social que conhece a história de sua comunidade, podem validar as informações levantadas sobre ela e exercer o controle social sobre o processo de regularização da terra.

Ademais, o conhecimento que têm os membros do CTU acerca de sua poligonal é fundamental para o levantamento de informação requerido para completar o processo de regularização da posse da terra. Essa referência a um espaço territorial concreto permite ordenar a participação cidadã em torno do processo de regularização da posse da terra e das atividades associadas a cada poligonal. Além disso, essas reivindicações associadas ao território fazem com que o espaço se converta em um dos elementos que proporciona identidade à pluralidade de habitantes.

Cada poligonal delimitada por cada CTU deve abranger, no máximo, 200 famílias, fato que define o âmbito de trabalho dos CTU como o espaço geográfico que contém as 200 famílias correspondentes, podendo cooperar ou coordenar esforços com outros CTU, setores ou subsetores, bairros ou urbanizações populares. A legitimidade dos CTU é dada por sua criação na Assembleia de Cidadãos, com a participação

\footnotetext{
${ }^{31}$ Giuffrida, L. y M. Salcedo (2005). Análisis y comprobación de los cambios de la dinámica urbana en las comunidades de Víctor Baptista, El Calvario, Rómulo Gallegos y El Naranjal con la introducción de los Comités de Tierra Urbanos. Comparación entre los casos de estudio y el modelo formal, Caracas, Universidad Simón Bolívar, mimeo. Pgs. 62-63
}

de, pelo menos, $50 \%$ das famílias que formam a poligonal correspondente.

Aliada à identidade territorial, a Carta de Bairro, que deve ser elaborada pelo CTU, expressa a identidade sociocultural daquele Comitê, pois nela se reconhece a história do bairro, desde sua fundação, e da comunidade que ali se estabeleceu, incluindo sua idiossincrasia e suas tradições, assim como as normas de convivência pactuadas coletivamente por essa comunidade. $\mathrm{O}$ valor político da Carta do Bairro advém do fato de que, além de dotá-lo de uma identidade comum, o acordo que estabelece a comunidade com base nessas normas mínimas de convivência compromete todos os membros em prol de um projeto coletivo ${ }^{32}$.

\section{Inclusão social e reconhecimento como sujeitos de direito: luta pelo di- reito à cidade}

$\mathrm{Na}$ atualidade, as demandas de regularização da posse da terra e de uma moradia digna ou adequada expressam o reclamo dos setores populares do direito a "viver na cidade", entendendose como um pleito para que sejam reconhecidos como cidadãos e, portanto, como sujeitos de direito. É assim que a luta pela terra não é tão somente uma demanda de caráter reivindicativo, mas também de um direito, o que a transforma em uma demanda política ${ }^{33}$. Por sua vez, esse conteúdo político guarda relação com o fato de que os setores populares são e consideram-se excluídos da

\footnotetext{
32 Um exemplo é o caso do bairro León Droz Blanco de Caracas, localizado nas redondezas da Universidade Central da Venezuela, sobre terrenos solicitados pela companhia de Metrô de Caracas. Dado ao fato de ter enfrentado várias ameaças de despejo, essa comunidade optou pela titularidade coletiva da terra. As formas de transferência e venda das benfeitoriade coletiva da tra. As formas de transferencia e venda das benfeitorias no marco da propriedade coletiva da terra, assim como sua luta contra os despejos, foram estabelecidas na Carta do Bairro dessa comunidade. Sem contar com leis que regulavam a matéria nem com precedente juridicos, os vizinhos construiram uma formula em que, ainda que cad família pudesse dispor de seu imóvel e do solo que ocupa, a propriedade deste é de uma Associação constituída pela totalidade das famílias do bairro, que, dentre outras coisas, encarrega-se de regular o uso do espaço (comum e familiar), autorizar as vendas ou os arrendamentos, estabelecer e zelar pelas normas de convivência, decidir sobre litígios e sobre ações de incumbência coletiva etc. (ANTILLANO, 2005, p. 214).

${ }^{33} \mathrm{~A}$ concepção da moradia como um direito básico não foi incorporada no passado pelos governos formalmente democráticos tampouco nos projetos dos partidos políticos que precederam o Presidente Chávez.
} 
cidade e, portanto, constroem sua identidade em torno do direito à cidadania.

Considerando que o estatuto da cidadania foi reconhecido e incorporado pela Constituição de 1999, suas demandas vão além da inclusão na cidade, tendo em vista que reivindicam a diversidade cultural e o direito a serem reconhecidos e a construir a cidade coletivamente dentro de uma visão plural onde todos caibam; isto é, reivindicam o direito à moradia sob novas formas ou modelos de cidade que requerem uma construção coletiva e plural.

Nas lutas dos CTU, expressase também uma identidade de classe, porquanto é justamente na condição de classe excluída em que reside o elemento de identidade do sujeito popular denominado CTU, que, ao ter sido excluído da cidade formal, foi obrigado a construir seu próprio hábitat.

Desse modo, coforme já explicitado, a luta por uma moradia digna transforma-se na luta pelo exercício de um direito político, como é o direito à participação e, em última instância, o direito a se inserir nos assuntos da cidade. Cabe destacar que esse tipo de participação pretende resgatar a forma de vida própria dos setores populares, $\mathrm{o}$ que significa que:

ao contrário da premissa segundo a qual nossos bairros devem ser urbanizados, e não contam com ordenação urbanística, se reconhece que expressam um esquema básico e primário de ordenação do espaço e de urbanismo, assim como uma idiossincrasia própria que devem ser respeitados e considerados e, inclusive, devem ser o ponto de partida em toda intervenção urbanística ${ }^{34}$.

Os CTU reivindicam o bairro como uma forma legítima de vida social e de ocupação do espaço. A regularização integral que propõem questiona $\mathrm{o}$

\footnotetext{
${ }^{33} \mathrm{~A}$ concepção da moradia como um direito básico não foi incorporada no passado pelos governos formalmente democráticos tampouco nos projepassado pelos governos formalmente democraticos tampouco
tos dos partidos políticos que precederam o Presidente Chávez.
}

modelo de consolidação de bairros, visto que suas intervenções são parciais e não respondem a diagnósticos integrais, fazendo com que a participação das comunidades dependa das instituições governamentais. Também se questiona o modelo de habilitação física de bairros (política contemplada na Lei do Subsistema de Moradia e Política Habitacional de 2000), pois, conforme a proposta dos CTU à Missão Moradia:

Dá-se ênfase aos aspectos financeiros e privilegia-se os aspectos construtivos sobre as outras dimensões próprias da vida e necessidades dos bairros, não reconhece $\mathrm{o}$ acervo $\mathrm{e}$ identidade dos assentamentos urbanos populares, impondo uma visão tecnocrática e alheia ao bairro, favorece a intermediação administrativa, política e técnica, relegando na prática as comunidades a convalidar as decisões de outros ${ }^{35}$.

Por meio da reivindicação cultural do modo de vida do bairro, os CTU, em conjunto com outros setores populares, advogam por uma democracia da diferença ou de igualdade complexa, isto é, pela "igualdade de oportunidades para afirmar a diferença e proteger-se contra mecanismos de exclusão social e discriminação cultural" ${ }^{36}$, independentemente das causas de tal exclusão. Os CTU propõem, assim, inserir a obrigatoriedade de sua participação na legislação referente às políticas públicas em matéria de moradia e habitação e nos espaços de decisão e, portanto, de poder, de modo a materializar a corresponsabilidade na definição das políticas do governo, fazendo com que este in-

\footnotetext{
${ }^{34}$ Asamblea Metropolitana de Comités de Tierra Urbana de Caracas (2004). Democratización de la ciudad y transformación urbana: propuespública, Oficina Técnica Nacional para la Regularización de la Tenencia de la Tierra. Pg. 8

${ }_{35}$ Asamblea Metropolitana de Comités de Tierra Urbana de Caracas (2004). Democratización de la ciudad y transformación urbana: propuesta de los CTU a la Misión Vivienda, Caracas, Vicepresidencia de la República, Oficina Técnica Nacional para la Regularización de la Tenencia de la Tierra. Pg. 7

${ }^{36}$ Hopenhayn, M. (2000). «Nuevas formas de ser ciudadano», Relea, $\mathrm{n}^{\circ}$

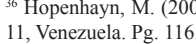

${ }^{37}$ Op. Cit. Pg. 7
} 
corpore as prioridades dos CTU e adote a proposta de transformação integral como uma política coerente de Estado, que transcenda as políticas de habitação dos governos anteriores.

É preciso destacar que a perspectiva de direitos não descarta a existência de algum tipo de vinculação com o Estado como garantidor dos direitos, já que reconhece a responsabilidade deste e da sociedade na gestão das políticas sobre direitos humanos em geral e sobre o direito à moradia em particular. Concebida assim a participação, os CTU demandam, além do direito a uma moradia adequada, a corresponsabilidade com o Estado na gestão dessa política, e não meros beneficiários de um programa.

Por essa razão, os CTU não se definem como autônomos pelo simples fato de serem não governamentais, mas pela relação que mantém com o Estado. Demandam a valorização da titularidade da posse da terra, que está associada à proteção dos indivíduos e das comunidades contra o despejo, e não somente ao valor mercantil da mesma; também demandam o direito à sua cultura e ao seu modo de vida e à democratização do solo, que consideram um instrumento fundamental não apenas para tornar viável uma política de moradia de alcance maciço, mas também para lograr o equilíbrio territorial ${ }^{37}$.

\section{Considerações finais}

Nas primeiras discussões que deram origem ao Decreto n. ${ }^{\circ} 1666$ e ao anteprojeto de lei que resultou na aprovação da Lei Especial de Regularização Integral da Posse da Terra dos Assentamentos Urbanos Populares, de 17 de julho de 2006, mostrou-se bastante evidente a dificuldade de regular a transferência da propriedade da terra a seus legítimos possuidores por meio exclusivamente de procedimentos administrativos e legais realizados pelo Estado. A precariedade das provas documentais (os chamados títulos suplementares), em um contexto cultural no qual a transferência dos imóveis se faz por meios informais e os contratos são celebrados através de acordos verbais, exigia que qualquer esforço pela regularização fundiária de assentamentos informais e precários nos bairros passasse pela validação e pelo controle da comunidade.

Por outro lado, a participação comunitária era entendida como meio para garantir a articulação da regularização da propriedade da terra com os processos de ordenação urbana e reabilitação física que deviam acompanhá-la. Por último, no final de 2001, o incremento da tensão política e da crescente mobilização popular parecia demandar o estímulo da organização social dos setores empobrecidos, base social do governo. Nesse contexto, surgem os Comitês de Terra Urbana (CTU).

Em virtude disso, o âmbito de atuação de um CTU não é só um espaço físico, mas também um espaço social, inclusivo e afetivo, definido pela identidade coletiva e pelas interações cotidianas entre os membros da comunidade. Ambos os fatores favorecem o conhecimento dos CTU sobre seu espaço específico, assim como os processos de participação e autogoverno.

Outra característica é sua legitimidade, já que são eleitos em assembleias com a participação majoritária dos vizinhos. A delimitação do âmbito em que se elege o CTU tem servido para a promoção de lideranças de escalas arraigadas no cotidiano.

É importante salientar, de igual modo, a flexibilidade da organização dos Comitês. Por um lado, se simplificam os procedimentos para a constituição de um CTU, para facilitar os processos de organização dos setores tradicionalmente alheios a participar nas organizações formais, uma vez que se faz desnecessária a presença de intermediários (partidos, agentes públicos e Organizações Não Governamentais ONG), por outro lado, não se prescreve nenhum esquema de organização, de 
modo que cada CTU se adéqua à idiossincrasia de sua comunidade.

Outro traço relevante é seu caráter autônomo. Embora os CTU nasçam como resultado de uma política de Estado, e é indubitável o predomínio de atores que simpatizam com a ação de Governo (provavelmente pelo apoio com que conta o Governo entre esses setores sociais), contam com um alto grau de autonomia em relação tanto do Estado quanto aos partidos. Diferentemente de outras formas de organização recentes, que são criadas como parte de programas institucionais e inclusive dependem, em muitos casos, funcionalmente de determinada agência governamental, os CTU funcionam de forma independente das Instituições. De qualquer modo, um dos fenômenos políticos mais interessantes e menos considerados dos últimos anos é a tensão participação-solidariedade e independência-conflito que se dá em relação aos setores mobilizados e às instituições governamentais.

Uma última característica se refere à especificidade funcional dos CTU. Nos últimos anos, a ação política tem sido deslocada de organizações que assumem interesses abstratos e universais a organizações que agem baseadas em interesses imediatos e específicos, mas não por isso menos políticos. Lutas que antes pareciam se reduzir à esfera meramente reivindicativa (tradicionalmente vista com desprezo pelos ativistas políticos) agora adotam prontamente conteúdos e modos de expressão políticos.

A luta pela água tem se convertido na luta de como se distribuem os serviços e de qual é o papel do Estado em sua prestação; as lutas salariais tornaram-se mobilizações pelo trabalho e contra o modelo econômico etc. No caso recente da Venezuela, têm prosperado, sobretudo, as formas de organização que respondem a demandas e objetivos específicos (mesas de água, comitês de saúde, cooperativas e CTU), enquanto declinam velhas formas de intermediação política, como os partidos, e novas formas de organização relacionadas com interesses difusos e indeterminados, como os Círculos Bolivarianos (CB) e os Conselhos Locais de Participação.

No caso dos Comitês de Terra, seus objetivos inscrevem-se no que, em seus próprios debates, tem-se chamado de "regularização integral dos bairros" e que poderia ser definido como um programa pela democratização da cidade e contra a segregação urbana.

Por todo o exposto, infere-se que os CTU consistem em uma instância efetiva de participação popular nas políticas públicas, de modo a fazer valer uma verdadeira cogestão com o Poder Público na luta pelo direito à moradia digna e em prol da efetivação do direito à cidade.

\section{Referências}

1. AFONSO DA SILVA, V. Direitos Fundamentais - Conteúdo Essencial, Restrições e Eficácia. São Paulo: Malheiros Editores, 2011.

2. Interpretação Constitucional. São Paulo: Malheiros Editores, 2010.

3. ALEXY, R. Teoria dos Direitos Fundamentais. Tradução de Virgílio Afonso da Silva. 5 ed. alemã. São Paulo: Malheiros Editores, 2008.

4. AMORIM, V. A. J. de. Direito Urbanístico- Legislação Urbanística e Estatuto da Cidade. São Paulo: Baraúna, 2011.

5. ANTILLANO, A. La lucha por el reconocimiento y la inclusión en los barrios populares: la experiencia de los Comités de Tierras Urbanas, Revista Venezolana de Economía y Ciencias Sociales, vol. 11, n. 3, 2005. Pg. 205218.

6. ARRUDA, G. M. C. A participação pública na defesa do meio ambiente: implementação de um desenvolvimen- 
to sustentável. In: Congresso Internacional de Direito Ambiental, 2., 1997, São Paulo. Anais ... São Paulo: Instituto O Direito por um Planeta Verde, 1997. p. 239-255.

7. ASAMBLEA METROPOLITANA DE COMITÉS DE TIERRA URBANA DE CARACAS. Democratización de la ciudad y transformación urbana: propuesta de los CTU a la Misión Vivienda, Caracas, Vicepresidencia de la República, Oficina Técnica Nacional para la Regularización de la Tenencia de la Tierra. 2004

8. BALDÓ, J. La política de vivienda para Venezuela, en C. Genatios, comp., Venezuela en perspectiva, p. 348-354, Caracas, Fondo Editorial Cuestión. 2004.

9. BARROSO, L. R. O Direito constitucional e a efetividade de suas normas: limites e possibilidades da Constituição Brasileira. $7^{\mathrm{a}} \mathrm{ed}$. Rio de Janeiro: Renovar, 2003.

10. BASTIDAS, C. Discurso de la democracia y el dilema representación-participación en Venezuela: 1979-2002. Tesis para optar al Titulo de Doctorado en Ciencia Política. Universidad Simón Bolívar. Manuscrito. 2007

11. BORJA, J. La ciudad conquistada, Madrid, Alianza Editorial. 2003.

12. CONTRERAS, V. Proyecto de Regularización de la Tenencia de la Tierra: Sector Toro Muerto, Municipio Caroní. EP-1420 Pasantías Cortas. Universidad Simón Bolívar, Manuscrito. 2005

13. Los retos de la Planificación Estratégica: Formulación del Plan Especial Participativo, Equitativo y Solidario del Sector Toro Muerto, Municipio Caroní. Trabajo de Grado para optar al Título de Urbanista. Universidad Simón Bolívar. Manuscrito. 2006

14. DATOS DE LA OFICINA TÉCNICA NACIONAL PARA LA RE-
GULARIZACIÓN DE LA TIERRA URBANA, 2007. Diario El Nacional (2006-2007). Caracas. Disponível em: hpp//: www.el-nacional.com.

15. ELLNER, S.; HELLINGER, D., eds. Venezuelan Politics in the Chávez Era: Class, Polarization and Conflic, Boulder, CO, Lynne Rienner Publishers, Inc. 2003

16. FRANÇA, R. L. Hermenêutica jurídica. $6^{\mathrm{a}}$ ed.. São Paulo: Saraiva, 1997.

17. GARCÍA-GUADILLA, M. P. Civil Society: Institutionalization, Fragmentation, Autonomy, en S. Ellner y D. Hellinger, eds., Venezuelan Politics in The Chávez Era: Class, Polarization and Conflict, pp. 179-196, Boulder, CO, Lynne Rienner Publishers Inc. 2033

18. "Nuevas organizaciones sociales bolivarianas y Comités de Tierra Urbanos: ¿Cooptación o Autonomía?". Trabajo presentado en la XXVI Conferencia Internacional de la Latin American Studies Association (LASA). Puerto Rico. 15-18 de marzo. 2006

19. Organizaciones sociales y conflictos sociopolíticos en una sociedad polarizada: las dos caras de la democracia participativa en Venezuela. Revista América Latina Hoy, v. 42, p. 37-60, 2006.

20. Ciudadanía y autonomía en las organizaciones sociales bolivarianas: los Comités de Tierra Urbana como movimientos sociales. Cuadernos del cendes, v. 24, n. 66, p. 47-73, 2007.

21. GIUFFRIDA, L.; SALCEDO, M. Análisis y comprobación de los cambios de la dinámica urbana en las comunidades de Víctor Baptista, El Calvario, Rómulo Gallegos y El Naranjal con la introducción de los Comités de Tierra Urbanos. Comparación entre los casos de estudio y el modelo formal, Caracas, Universidad Simón Bolívar, mimeo. 2005

22. HAWKINS, K.; HANSEN, D. De- 
pendent Society: the Círculos Bolivarianos in Venezuela. Latin American Research Review, v. 41, n. 1, 2006.

23. KATSIAFICAS, G. El significado de la autonomía, Caosmosis, Diponivel em: <http//caosmosis.acracia.net $>$ 2007.

24. LÓPEZ MAYA, M. Popular Protest in Venezuela: Novelties and Continuities, Latin American Perspectives, v. 32, n. 2, p. 92-108, 2005.

25. MARMELSTEIN, G. Curso de Direitos Fundamentais. 2 ed.. São Paulo: Atlas, 2009.

26. NEGRÓN, M. Ciudad formal y ciudad informal: una sola ciudad, Revista Investigación y Gerencia, v. 7, n. 33, 1990.

27. RESTREPO, D. .Eslabones y Precipicios: entre participación y democracia, Revista Paraguaya de Sociología, n. 107 , p. 77-102.

28. RIVAS, M. El problema de los barrios, Revista SIC, n. 665, p. 211-221, 2004.

29. SAULE JÚNIOR, N. Instrumentos de Destinação Social dos Imóveis da União. Revista Magister de Direito Ambiental e Urbanístico, v. 26, p. 5280, 2009.

30. O Direito à Cidade como Resposta ã Exclusão Social e à Segregação Espacial. Revista Magister de Direito Ambiental e Urbanístico, v. 20, p. 7-43, 2008.

31. Legal Frameworks for citizens Participation:Synthesis Report, Research Report Series, Logolink Learning Iniciative on Citizens Participation and Governance. IDS - Institute of Development Studies, Brighton, UK, 2003.

32. . Políticas Públicas e Direitos Humanos. Caderno Pólis, v. 1, n. 3 , p. 1-32, 2001.

33. . O Direito à Moradia. Polí- ticas Públicas e Inclusão Social. Caderno de Pesquisa CEBRAP, n. 7, 1997.

34. Moradia nos Assentamentos Irregulares. $1^{a}$ ed. Porto Alegre: Sergio Antonio Fabris Editor, 2004.

35. Direito à Cidade - Trilhas Legais para o Direito às Cidades Sustentáveis. São Paulo: Editora Max Limonad, 1999.

36. . A Participação dos Cidadãos no Controle da Administração Pública. Revista de Direito da Universidade Ibirapuera, v. 1, p. 199-240, 1998. 